\title{
Comparative Effects of Intragastric and Intraduodenal Administration of Quinine on the Plasma Glucose Response to a Mixed-Nutrient Drink in Healthy Men: Relations with Glucoregulatory Hormones and Gastric Emptying
}

Braden D Rose, ${ }^{1}$ Vida Bitarafan, ${ }^{1}$ Peyman Rezaie, ${ }^{1}$ Penelope CE Fitzgerald, ${ }^{1}$ Michael Horowitz, ${ }^{1,2}$ and Christine Feinle-Bisset ${ }^{1}$

${ }^{1}$ Adelaide Medical School and Centre of Research Excellence in Translating Nutritional Science to Good Health, University of Adelaide, Adelaide, South Australia 5000, Australia; and ${ }^{2}$ Endocrine and Metabolic Unit, Royal Adelaide Hospital, Adelaide, Australia

\begin{abstract}
Background: In preclinical studies, bitter compounds, including quinine, stimulate secretion of glucoregulatory hormones [e.g., glucagon-like peptide-1 (GLP-1)] and slow gastric emptying, both key determinants of postprandial glycemia. A greater density of bitter-taste receptors has been reported in the duodenum than the stomach. Thus, intraduodenal (ID) delivery may be more effective in stimulating GI functions to lower postprandial glucose.

Objective: We compared effects of intragastric (IG) and ID quinine [as quinine hydrochloride (QHCI)] administration on the plasma glucose response to a mixed-nutrient drink and relations with gastric emptying, plasma C-peptide (reflecting insulin secretion), and GLP-1.

Methods: Fourteen healthy men [mean \pm SD age: $25 \pm 3$ y; BMl (in $\mathrm{kg} / \mathrm{m}^{2}$ ): $22.5 \pm 0.5$ ] received, on 4 separate occasions, in double-blind, randomly assigned order, $600 \mathrm{mg} \mathrm{OHCl}$ or control, IG or ID, $60 \mathrm{~min}$ (IG conditions) or $30 \mathrm{~min}$ (IG conditions) before a mixed-nutrient drink. Plasma glucose (primary outcome) and hormones were measured before, and for $2 \mathrm{~h}$ following, the drink. Gastric emptying of the drink was measured using a ${ }^{13} \mathrm{C}$-acetate breath test. Data were analyzed using repeated-measures 2-way ANOVAs (factors: treatment and route of administration) to evaluate effects of $\mathrm{OHCl}$ alone and 3-way ANOVAs (factors: treatment, route-of-administration, and time) for responses to the drink.

Results: After $\mathrm{QHCl}$ alone, there were effects of treatment, but not route of administration, on C-peptide, GLP-1, and glucose $(P<0.05)$; $\mathrm{QHCl}$ stimulated C-peptide and GLP-1 and lowered glucose concentrations (IG control: $4.5 \pm 0.1$; IG-QHCl: $3.9 \pm 0.1$; ID-control: $4.6 \pm 0.1$; ID-QHCl: $4.2 \pm 0.1 \mathrm{mmol} / \mathrm{L})$ compared with control. Postdrink, there were treatment $\times$ time interactions for glucose, C-peptide, and gastric emptying, and a treatment effect for GLP-1 (all $P<0.05$ ), but no route-of-administration effects. QHCl stimulated C-peptide and GLP-1, slowed gastric emptying, and reduced glucose (IG control: $7.2 \pm 0.3$; IG-QHCl: $6.2 \pm 0.3$; ID-control: $7.2 \pm 0.3$; ID-QHCl: $6.4 \pm 0.4 \mathrm{mmol} / \mathrm{L}$ ) compared with control.

Conclusions: In healthy men, IG and ID quinine administration similarly lowered plasma glucose, increased plasma insulin and GLP-1, and slowed gastric emptying. These findings have potential implications for lowering blood glucose in type 2 diabetes. This study was registered as a clinical trial with the Australian New Zealand Clinical Trials at www.anzctr.org.au as ACTRN12619001269123. J Nutr 2021;151:1453-1461.
\end{abstract}

Keywords: postprandial blood glucose, gastric function, bitter taste, glucoregulatory hormones, human

\section{Introduction}

Meal ingestion modulates a number of gastrointestinal (GI) functions, including the secretion of glucoregulatory hormones and gastric emptying, which are major determinants of postprandial blood glucose concentrations $(1,2)$. Ingestion, or intragastric or intraduodenal administration, of nutrients, e.g., protein, fatty acids or amino acids, as a 'preload' before a meal, potently stimulates these functions (3-6). Glucagon-like 
peptide-1 (GLP-1) is of particular interest, given that it has been shown to be a physiological modulator of postprandial glycemia by glucose-dependent stimulation of insulin and suppression of glucagon (7) and slowing of gastric emptying (8-10). Moreover, GLP-1 agonists and dipeptidyl peptidase 4 inhibitors (which increase endogenous GLP-1) are now used extensively in the management of type 2 diabetes $(11,12)$. Gastric emptying plays a key role in the postprandial glycemic response by regulating the delivery, and subsequent absorption, of nutrients in the small intestine, as well as the release of glucoregulatory hormones, including GLP-1 (13).

There has been an increased interest in the therapeutic potential of bitter compounds, subsequent to preclinical observations that they modulate both glucoregulatory hormones and gastric emptying, by stimulating bitter-taste receptors (TAS2Rs), present throughout the GI tract (14-21). For example, berberine, denatonium benzoate, and phenylthiourea stimulate the release of GLP-1 from the human enteroendocrine cell lines NCI-H716 and HuTu-80 (18-20). Furthermore, both an extract of bitter gourd and denatonium benzoate, administered intragastrically, stimulate GLP-1 secretion and reduce blood glucose in mice $(19,21)$. Furthermore, denatonium benzoate increases contractility in both fundic and antral muscle strips from mice, chloroquine and phenylthiocarbamide modulate smooth muscle contractility, and intragastric denatonium benzoate and phenylthiocarbamide slow gastric emptying in mice, via TAS2Rs (15). Denatonium benzoate also increased plasma insulin and reduced plasma glucose, following glucose gavage $(5 \mathrm{~g} / \mathrm{kg})(19)$, and the glucose-lowering effect of wild bitter gourd was abolished by pretreatment with the GLP1 antagonist exendin(9-39)amide, suggesting a key role for GLP-1 (22).

There is only limited, as well as inconsistent, information about the effects of bitter compounds in humans. Intragastric administration of $100 \mathrm{mg}$ bitter secoiridoids, an extract from the root of Gentiana lutea, was reported to have a small, albeit statistically nonsignificant, effect to stimulate GLP-1 (23). Intraduodenal infusion of quinine, at doses of $37.5-225 \mathrm{mg}$, over a 60-min period, had no effects on either plasma GLP1 or antropyloroduodenal pressures $(3,24)$, however, the low infusion rate $(2 \mathrm{~mL} / \mathrm{min})$ may have been insufficient to reach a critical threshold for activation of TAS2Rs. In support of this concept, in our recent study, intragastric administration of 275 or $600 \mathrm{mg}$ quinine enhanced the plasma insulin and GLP-1 response to a mixed-nutrient drink consumed $30 \mathrm{~min}$ later, associated with a reduction in plasma glucose, but no effect on gastric emptying (25). While the latter observation was consistent with the outcome of a study using a much lower dose of quinine $(18 \mathrm{mg}$ ) (26), it is also possible that the time interval of 30 min between quinine administration and drink consumption may have been insufficient for quinine to reach intestinal TAS2Rs at a sufficient concentration to induce feedback slowing of gastric emptying. This is supported

BDR, VB, and PR contributed equally to this article

Funding disclosure: VB and PR were supported by Adelaide Scholarships International provided by the University of Adelaide (VB, 2017-2020; PR, 20182021), and CFB by an NHMRC Senior Research Fellowship (grant 1103020, 2016-2021). The research was funded by an NHMRC Project Grant to CFB (grant 1158296, 2019-2022).

Author disclosures: The authors report no conflicts of interest.

Address correspondence to CF-B (e-mail: christine.feinle@adelaide.edu.au).

Abbreviations used: CCK, cholecystokinin; GI, gastrointestinal; GLP-1, glucagonlike peptide-1; ID, intraduodenal; IG, intragastric; $\mathrm{QHCl}$, quinine hydrochloride; TAS2Rs, bitter-taste receptors; VAS, visual analog scale by evidence from studies in mice to indicate a variable regional distribution of TAS2Rs subtypes along the GI tract, with a greater density of receptors in the duodenum than the stomach (14). Accordingly, delivery of quinine to the duodenum, and/or varying the timings of delivery between the stomach and duodenum, may potentially affect the release of glucoregulatory hormones, gastric emptying, and postprandial glycemia differently.

The aim of the current study was to evaluate the comparative effects of intragastric and intraduodenal administration of quinine on the plasma glucose, C-peptide, and GLP-1 responses to, and gastric emptying of, a mixed-nutrient drink, in healthy men.

\section{Methods}

\section{Study participants}

Fourteen healthy male participants (mean age: $25 \pm 2$ y; BMI: $22.5 \pm 0.5)$ participated in the study (Figure 1). The number of participants was determined using power calculations based on our previous work (25). We calculated that $n=14$ participants would allow the detection of a $0.8 \mathrm{mmol} / \mathrm{L}$ difference in peak plasma glucose, which usually occurs approximately $30 \mathrm{~min}$ after ingestion of a mixed-nutrient drink, with an SD of $1.1 \mathrm{mmol} / \mathrm{L}$, at $\alpha=0.05$ and a power of $80 \%$. Participants were recruited through flyers placed around local universities and the Royal Adelaide Hospital and advertisements in local newspapers. Participants were screened before their inclusion to exclude those with GI symptoms or a history of GI disease or surgery, vegetarians, smokers, an alcohol consumption of $>20 \mathrm{~g} / \mathrm{d}$ on $>5 \mathrm{~d} / \mathrm{wk}$, use of medications known to affect appetite, energy intake, or GI function; high-performance athletes; unstable body weight ( $\geq 5 \%$ change over the last 3 mo before participation) and restrained eaters (score $>12$ on the restrained eating component of the 3 -factor eating questionnaire) (27). The study protocol was approved by the Human Research Ethics Committee of the Central Adelaide Local Health Network and performed in accordance with the Declaration of Helsinki. All participants provided written informed consent before their inclusion. Once participants were enrolled, they were assigned to 1 of 14 treatment orders (i.e., $n=1$ randomly assigned to each combination), using balanced random assignment generated with an online tool (www.randomization.com), by a research officer who was not involved in data analysis. Participants were compensated for the time they spent involved in the study at a rate of AU $\$ 18 / \mathrm{h}$, as approved by the Ethics Committee.

\section{Study outline}

In a pilot study in 8 healthy male participants (mean age: $25 \pm 3 \mathrm{y}$; BMI: $21.9 \pm 0.6 \mathrm{~kg} / \mathrm{m}^{2}$ ), we determined the temporal profiles of the plasma insulin and pyloric pressure (as a key determinant for the slowing of gastric emptying) responses to intragastric (IG) and intraduodenal (ID) bolus administration of $600 \mathrm{mg}$ quinine hydrochloride $(\mathrm{QHCl})$, dissolved in $10 \mathrm{~mL}$ distilled water (IG-QHCl and ID$\mathrm{QHCl}$, respectively). Plasma insulin concentrations (means \pm SEMs) peaked $\sim 66 \pm 7 \mathrm{~min}$ after IG-QHCl, and $\sim 33 \pm 4$ min after ID$\mathrm{QHCl}$, while the peak number of pyloric pressure waves occurred $\sim 59 \pm 17$ min after IG-QHCl, and $\sim 29 \pm 4$ min after ID-QHCl. Thus, IG-QHCl and ID-QHCl appeared to have maximum effects on plasma insulin and pyloric pressures at $\sim 60 \mathrm{~min}$ and $30 \mathrm{~min}$, respectively, after administration. We therefore evaluated the effects of $600 \mathrm{mg}$ IG$\mathrm{QHCl}$ or ID-QHCl, or IG-control or ID-control, administered $60 \mathrm{~min}$ (IG conditions) or $30 \mathrm{~min}$ (ID conditions) before a mixed-nutrient drink (Figure 2). The effect of quinine on plasma glucose was the primary outcome, and effects on gastric emptying, and plasma GLP1 and C-peptide, were secondary outcomes. The 600-mg dose of QHCl was selected as it lowered postprandial blood glucose in our previous study (25). 


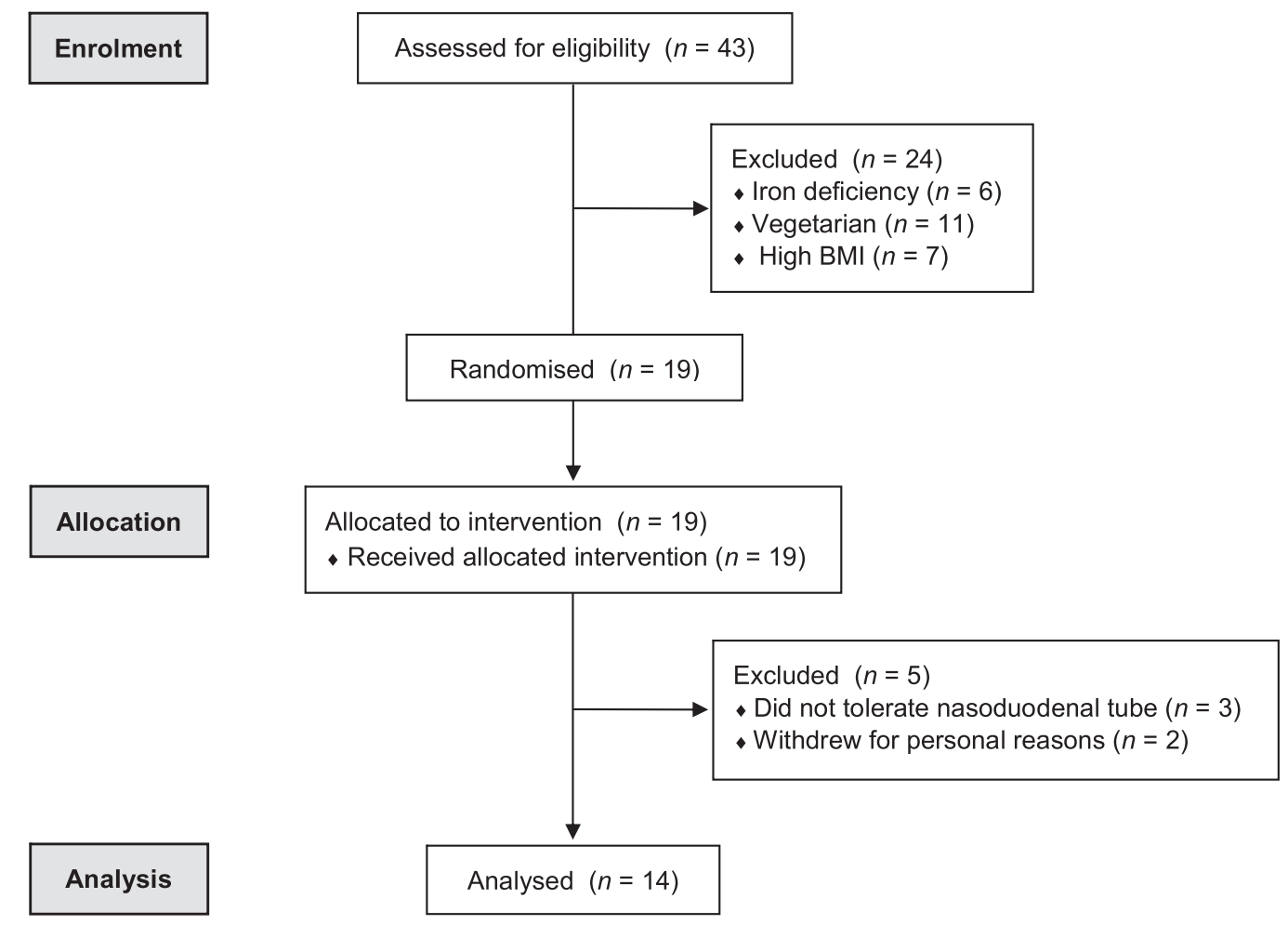

FIGURE 1 CONSORT flow diagram.

\section{Preparation of treatments}

The QHCl treatment was prepared by dissolving $600 \mathrm{mg} \mathrm{QHCl}$ (Sinkona Indonesia Lestari) in $10 \mathrm{~mL}$ distilled water. The control treatment consisted of $10 \mathrm{~mL}$ distilled water. The treatments were prepared on the morning of each study day, and filled in syringes, by a research officer who had no involvement in data analysis, and administered at a temperature of $\sim 30^{\circ} \mathrm{C} . \mathrm{QHCl}$ and control treatments were indistinguishable, so that both the study participants and the investigators performing the study were blinded.

\section{A: Intragastric administration}

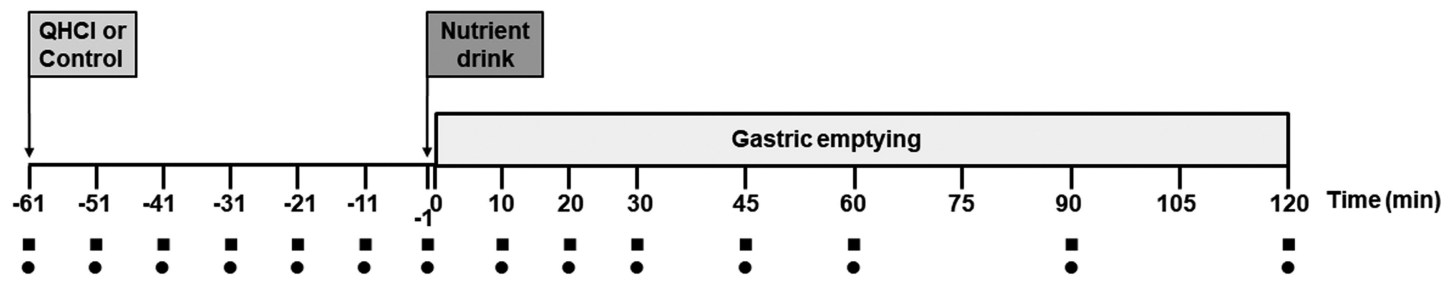

\section{B: Intraduodenal administration}

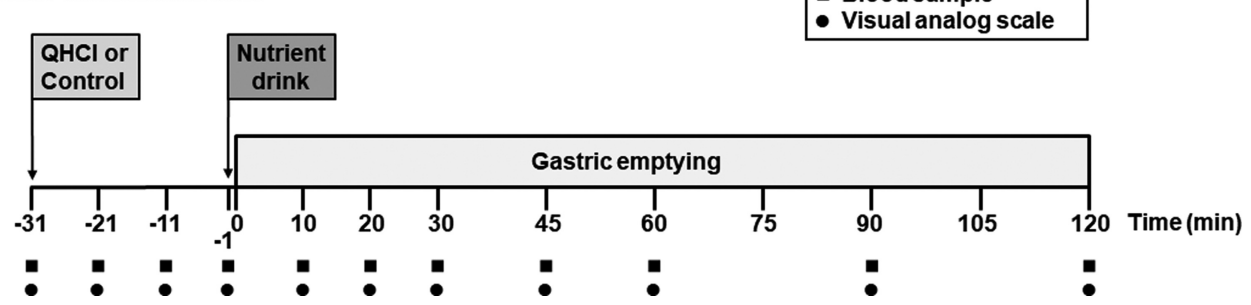

FIGURE 2 Schematic representation of the study design. (A) Study protocol for IG administration. At $t=-61$ min, after completion of phase III and during phase I of fasting motor activity, a baseline blood sample and VAS ratings were collected, then either QHCl or control was administered intragastrically within 1 min. 60 min later, at $\mathrm{t}=-1 \mathrm{~min}$, each participant consumed, within $1 \mathrm{~min}, 350 \mathrm{~mL}$ of a mixed-nutrient drink, containing $100 \mathrm{mg}$ of ${ }^{13} \mathrm{C}$-acetate for measurement of gastric emptying by ${ }^{13} \mathrm{CO}_{2}$ breath test. Blood samples, VAS ratings, and breath samples were collected at the indicated time points throughout the study. (B) Study protocol for ID administration. On ID study days, the protocol was identical to that on IG days, except the mixed-nutrient drink was consumed 30 min after administration of $\mathrm{QHCl}$ or control, which occurred at $\mathrm{t}=-31 \mathrm{~min}$, and blood sampling was adjusted accordingly. ID, intraduodenal; IG, intragastric; $\mathrm{QHCl}$, quinine hydrochloride; VAS, visual analog scale. 


\section{Study protocol}

Participants were studied on 4 occasions, each separated by $3-7 \mathrm{~d}$ in a randomized, double-blind fashion. Participants were instructed to refrain from vigorous physical activity and alcohol consumption for $24 \mathrm{~h}$ prior to each study and provided with a standardized meal (beef lasagne; total energy content: $602 \mathrm{kcal}$; McCain Food) to be consumed by 19:00 the night prior to each study visit. The following morning, participants attended the Clinical Research Facility at the Adelaide Medical School, University of Adelaide, at 08:15 after an overnight fast (from both solids and fluids except water after 19:00, and from water after 06:30).

Upon arrival, participants were intubated with a manometric catheter (Dentsleeve International, Mui Scientific; total length: $100 \mathrm{~cm}$; external diameter: $3.5 \mathrm{~mm}$ ), which was inserted through an anesthetized nostril into the stomach and positioned across the pylorus as described previously $(4,5,28)$. The most proximal antral channel was used for IG administration, and an additional infusion channel, located $\sim 14.5 \mathrm{~cm}$ distal to the pylorus, for ID administration. Once the catheter was in position [within $\sim 49 \pm 8$ min (mean \pm SEM) across study days and participants], an intravenous cannula was placed into a forearm vein and the arm wrapped in a heat pad for regular sampling of arterialized blood. Immediately following the completion of phase III of the fasting migrating motor complex (i.e., during phase I, a period of motor quiescence), data from a baseline blood sample and visual analog scale (VAS) questionnaire to assess GI symptoms were collected. After fasting motility was monitored for $10 \mathrm{~min}, \mathrm{QHCl}$ or control was administered into either the stomach $(\mathrm{t}=-61 \mathrm{~min})$ or duodenum $(\mathrm{t}=-31 \mathrm{~min})$, and the catheter was then removed. At $\mathrm{t}=-1 \mathrm{~min}$, participants consumed, within $1 \mathrm{~min}$, a 350-mL mixed-nutrient drink (Resource plus; Nestle, $325 \mathrm{~mL}: 500 \mathrm{kcal}, 74 \mathrm{~g}$ carbohydrates, including maltodextrin and sucrose, $18 \mathrm{~g}$ protein, and $15 \mathrm{~g}$ fat, plus $25 \mathrm{~mL}$ water to make up the final volume), which included $100 \mathrm{mg}{ }^{13} \mathrm{C}$-acetate for measurement of gastric emptying by breath test (29). Blood samples for measurement of plasma glucose, C-peptide, and GLP-1 concentrations, VAS ratings, and breath samples were collected at regular time intervals. At $t=120 \mathrm{~min}$, the intravenous cannula was removed, and each participant was provided with a light lunch, after which they were allowed to leave the laboratory.

On a separate day, oral taste detection thresholds for $\mathrm{QHCl}$ were quantified to ensure that all participants detected $\mathrm{QHCl}(25)$.

\section{Measurements}

\section{Oral quinine taste thresholds.}

Oral detection thresholds for $\mathrm{QHCl}$ were quantified using the ascending-series 3-alternative forced-choice technique (30) and concentrations described in detail elsewhere (25).

\section{Plasma glucose and hormone analyses.}

Blood samples were collected into ice-chilled ethylenediaminetetraacetic acid tubes and centrifuged at $\sim 1832 \times g$ for $1 \mathrm{~min}$ at $4^{\circ} \mathrm{C}$ within $15 \mathrm{~min}$ of collection, before being stored at $-80^{\circ} \mathrm{C}$ until subsequent analysis.

Plasma glucose concentrations $(\mathrm{mmol} / \mathrm{L})$ were measured by the glucose oxidase method, using a glucose analyzer (YSI 2300 Stat Plus, Yellow Springs Instruments). Plasma C-peptide concentrations (pmol/L), a measure of insulin secretion (31), were quantified using an ELISA immunoassay (10-1136-01, Mercodia) (32). Plasma total GLP1 concentrations $(\mathrm{pmol} / \mathrm{L})$ were quantified using a radioimmunoassay (GLPIT-36HK, Millipore) (25).

\section{Gastric emptying.}

${ }^{13} \mathrm{CO}_{2}$ concentrations in end-expiratory breath samples were measured using an isotope ratio mass spectrometer (FANCi; Fischer Analysen Instrumente $\mathrm{GmbH}$ ). The results were expressed as percentage of ${ }^{13} \mathrm{CO}_{2}$ recovery/h and profiles plotted as cumulative values over the sampling period (29).

\section{GI symptoms.}

Nausea and bloating were evaluated using a 100-mm VAS questionnaire (33). Participants rated how they were feeling at a given time point by placing a vertical stroke at the appropriate point on each line.

\section{Data and statistical analysis}

Statistical analysis was performed using SPSS software (version 26.0; IBM). Plasma glucose, C-peptide, and GLP-1 concentrations and gastric emptying data were expressed as absolute values, while VAS scores were expressed as changes from baseline.

Effects of $\mathrm{QHCl}$ alone (i.e., prior to ingestion of the mixednutrient drink) on plasma glucose, C-peptide, and GLP-1 concentrations and VAS ratings were evaluated by calculating mean values, i.e., mean -61 to -1 min and mean -31 to -1 min, so the 2 baseline periods could be compared, despite different durations. These means, as well as the effects at $\mathrm{t}=-1 \mathrm{~min}$, were analyzed using repeatedmeasures 2-way ANOVAs with treatment (QHCl, control) and route of administration (IG, ID) as factors. To evaluate responses to the mixednutrient drink, plasma glucose, C-peptide, GLP-1, and gastric emptying were analyzed using repeated-measures 3-way ANOVAs with treatment $(\mathrm{QHCl}$, control), route of administration (IG, ID), and time $(\mathrm{t}=0$ $120 \mathrm{~min}$ for plasma glucose, C-peptide, GLP-1 at 7 levels, i.e., $\mathrm{t}=10$, 20, 30, 45, 60, 90, $120 \mathrm{~min}$; for gastric emptying at 17 levels, i.e., $\mathrm{t}=0$, $5,10,15,20,25,30,35,40,45,50,55,60,75,90,105$, and $120 \mathrm{~min}$ ) as factors. Peak plasma glucose, and time to peak concentrations, as well as VAS ratings, expressed as AUCs ( $\mathrm{AUC}_{-1}$ to $120 \mathrm{~min}$ ), were analyzed using repeated-measures 2-way ANOVAs with treatment ( $\mathrm{QHCl}$, control) and route of administration (IG, ID) as factors. Post hoc comparisons, with $P$ values adjusted for multiple comparisons by Bonferroni's correction, were performed where ANOVAs revealed significant main effects or interaction. Sphericity of the time effect was evaluated by Mauchly's test and, when violated, the adjusted Greenhouse-Geisser $P$ value was reported. Normality and variance assumptions of ANOVA analyses were assessed via residual plots and were acceptable for all models. Correlations between plasma glucose at $\mathrm{t}=-1$ to $30 \mathrm{~min}$ (expressed as $\mathrm{AUC}_{-1}$ to $30 \mathrm{~min}$ ), reflecting the early glucose response, with gastric emptying between $\mathrm{t}=0-30\left(\mathrm{AUC}_{0-30} \mathrm{~min}\right)$ and C-peptide and GLP-1, both at $\mathrm{t}=-1 \mathrm{~min}$ and between $\mathrm{t}=-1$ to $30 \mathrm{~min}\left(\mathrm{AUC}_{-1}\right.$ to $30 \mathrm{~min}$ ), were evaluated, using data across all study days, with the use of linear within-subject correlations (34). All data are reported as means \pm SEMs. All tests were 2-tailed, and differences were considered statistically significant at $P \leq 0.05$.

\section{Results}

All participants tolerated the study treatments well and completed all study visits without reporting any adverse effects. $\mathrm{QHCl}$ was detected orally in all participants, with a mean detection threshold of $0.15 \pm 0.06 \mathrm{mmol} / \mathrm{L}$. Breath test data were unavailable in 2 participants due to technical problems.

\section{Plasma glucose concentrations}

There were no differences in baseline concentrations of plasma glucose between study days. (Figure 3A).

\section{Response to $\mathrm{QHCl}$ alone.}

There were effects of treatment, but not of route of administration, on mean plasma glucose concentration $(P<0.001)$ and plasma glucose at $\mathrm{t}=-1 \min (P=0.017) ; \mathrm{QHCl}$ reduced mean plasma glucose $(P=0.017)$ and plasma glucose at $\mathrm{t}=$ -1 min $(P<0.001)$, albeit modestly, compared with control (Figure 3A, Table 1).

\section{Response to the drink.}

Plasma glucose increased on all study days. There was a treatment $\times$ time interaction $(P=0.001)$, but no effect of route of administration, on plasma glucose concentrations; $\mathrm{QHCl}$ reduced plasma glucose between $\mathrm{t}=10-45 \mathrm{~min}$, compared with control (all $P<0.0 .24$ ) (Figure 3A). There were effects of treatment, but not of route of administration, on both peak plasma glucose $(P=0.001)$ and the time to peak glucose 

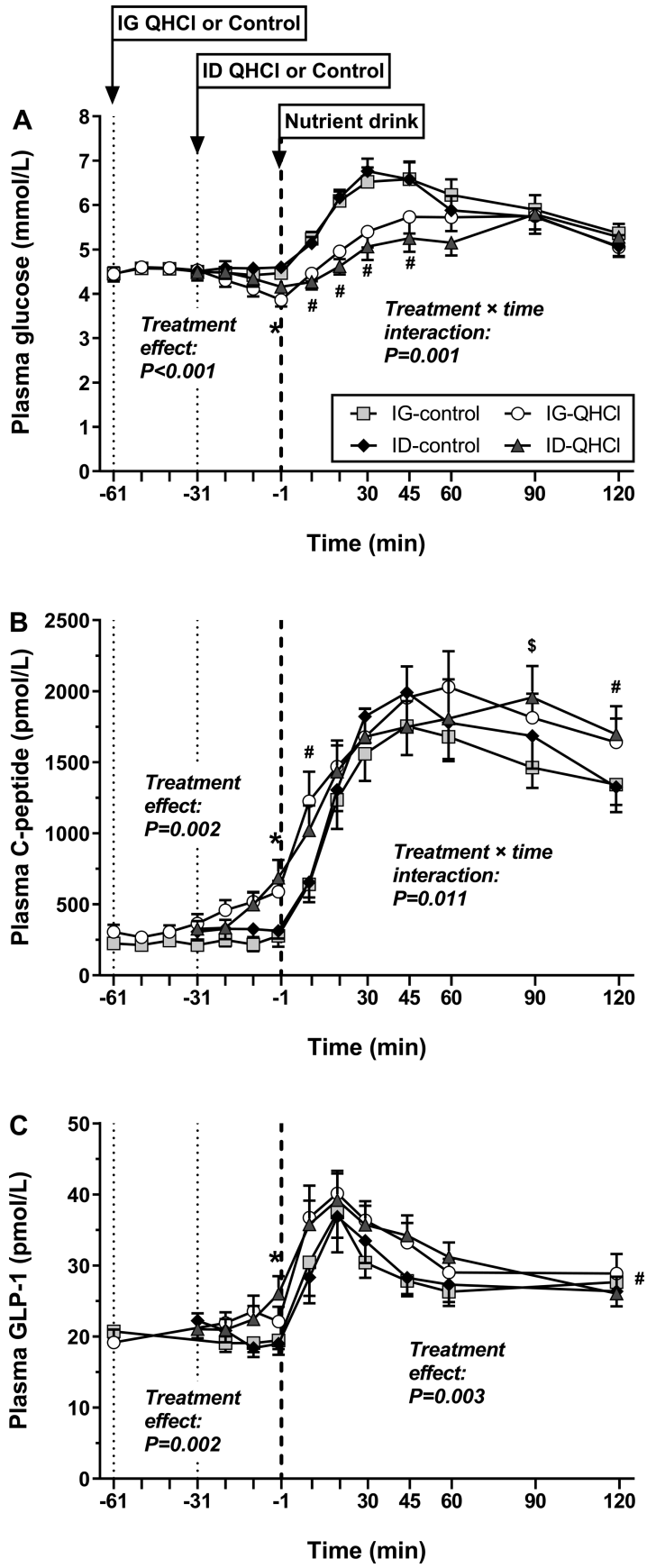

FIGURE 3 Plasma glucose (A), C-peptide (B), and GLP-1 (C) concentrations after IG $\mathrm{QHCl}$ or control ( $\mathrm{t}=-61$ to $-1 \mathrm{~min}$ ), or ID $\mathrm{QHCl}$ or control ( $\mathrm{t}=-31$ to $-1 \mathrm{~min}$ ), and after a mixed-nutrient drink ( $\mathrm{t}=0-120 \mathrm{~min}$ ) in healthy men. To evaluate effects of $\mathrm{OHCl}$ alone, data were analyzed using repeated-measures 2-way ANOVAs (factors: treatment, route of administration), to evaluate responses to the drink, we used repeated-measures 3-way ANOVAs (factors: treatment, route of administration, time). (A) Response to $\mathrm{QHCl}$ alone: $\mathrm{OHCl}$ and control differ at that time, ${ }^{*} P<0.001$. Response to the drink: $\mathrm{QHCl}$ and control differ at that time, all $\# P<0.024$. (B) Response to $\mathrm{QHCl}$ alone: $\mathrm{QHCl}$ and control differ at that time, ${ }^{*} P=0.002$. Response to the drink: $\mathrm{OHCl}$ and control differ at that time, both $\# P<0.008$, and trend for $\mathrm{QHCl}$ and control to differ at that time, $\$ P=0.052$. (C) Response to $\mathrm{QHCl}$ alone: $\mathrm{QHCl}$ and control differ at that time, ${ }^{*} P=0.002$. Response to the drink: $\mathrm{QHCl}$ and control differ, $\# P=0.003$. Blood samples were not analyzed for GLP-1 at $\mathrm{t}=-51$, $-41,-31$ and 90 min on IG study days and at $t=90$ min on ID study days. Data are means \pm SEMs; $n=14$. GLP-1, glucagon-like peptide$1 ; \mathrm{ID}$, intraduodenal; IG, intragastric; $\mathrm{QHCl}$, quinine hydrochloride.
$(P=0.006)$; $\mathrm{QHCl}$ lowered peak glucose, $(P=0.006)$ and increased the time to peak glucose $(P=0.001)$, compared with control (Table 1).

\section{Plasma C-peptide concentrations}

There were no differences in baseline C-peptide concentrations between study days (Figure 3B).

\section{Response to $\mathrm{OHCl}$ alone.}

There were effects of treatment, but not of route of administration, on mean plasma C-peptide concentration $(P=0.002)$ and concentrations at $\mathrm{t}=-1 \min (P=0.001) ; \mathrm{QHCl}$ increased mean C-peptide $(P=0.002)$ and concentration at $\mathrm{t}=-1 \mathrm{~min}$ $(P=0.001)$, albeit modestly, compared with control $(P<0.05)$ (Figure 3B, Table 1).

\section{Response to the drink.}

Plasma C-peptide increased markedly on all study days. There was a treatment $\times$ time interaction $(P=0.011)$, but no effect of route of administration, on plasma C-peptide; $\mathrm{QHCl}$ increased C-peptide at $\mathrm{t}=10$ and $120 \mathrm{~min}$ (both $P<0.008$ ), and tended to stimulate C-peptide at $\mathrm{t}=90 \mathrm{~min}(P=0.052)$, compared with control (Figure 3B).

\section{Plasma GLP-1 concentrations}

There were no differences in baseline GLP-1 concentrations between study days (Figure 3C).

\section{Response to $\mathrm{OHCl}$ alone.}

There were effects of treatment, but not of route of administration, on mean plasma GLP-1 concentration $(P=0.002)$ and concentrations at $\mathrm{t}=-1 \min (P=0.011) ; \mathrm{QHCl}$ increased mean plasma GLP-1 concentration $(P=0.002)$ and concentrations at $\mathrm{t}=-1 \min (P=0.011)$, albeit modestly, compared with control (Figure 3C, Table 1).

\section{Response to the drink.}

Plasma GLP-1 increased markedly on all study days. There was an effect of treatment $(P=0.003)$, but not of route of administration, on plasma GLP-1; QHCl increased plasma GLP-1 compared with control $(P=0.003)$ (Figure 3C).

\section{Gastric emptying}

There was a treatment $\times$ time interaction, but no effect of route of administration, on gastric emptying of the drink $(P=0.003)$; QHCl slowed gastric emptying modestly between $t=20-$ 75 min, compared with control (all $P<0.016$ ) (Figure 4).

\section{Relations between plasma glucose with gastric emptying, C-peptide, or GLP-1}

There was a direct correlation between early plasma glucose $\mathrm{AUC}_{-1}$ to $30 \mathrm{~min}$ and early gastric emptying $\mathrm{AUC}_{0-30 \text { min }}$ $(r=0.621, P<0.001)$, and an inverse correlation with Cpeptide at $\mathrm{t}=-1 \mathrm{~min}(r=-0.265, P=0.048)$. There were no correlations between early plasma glucose $\mathrm{AUC}_{-1}$ to $30 \mathrm{~min}$ and early C-peptide $\mathrm{AUC}_{-1}$ to $30 \mathrm{~min}$, GLP-1 $\mathrm{AUC}_{-1}$ to $30 \mathrm{~min}$ or GLP-1 at $\mathrm{t}=-1 \mathrm{~min}$.

\section{GI symptoms}

There were no effects of treatment or route of administration on ratings of nausea or bloating, either in response to $\mathrm{QHCl}$ alone, or the mixed-nutrient drink (Figure 5). 
TABLE 1 Mean concentrations and concentrations at $\mathrm{t}=-1 \mathrm{~min}$, of plasma glucose and hormones following IG or ID administration of $600 \mathrm{mg} \mathrm{QHCl}$ or control, and peak and time to peak of plasma glucose after consumption of a mixed-nutrient drink in healthy men ${ }^{1}$

\begin{tabular}{|c|c|c|c|c|c|}
\hline & $\begin{array}{l}\text { IG and } \\
\text { control }\end{array}$ & $\begin{array}{c}\mathrm{IG} \text { and } \\
\mathrm{OHCl}\end{array}$ & $\begin{array}{l}\text { ID and } \\
\text { control }\end{array}$ & $\begin{array}{l}\mathrm{ID} \text { and } \\
\mathrm{OHCl}\end{array}$ & $\begin{array}{c}P \text { value } \\
\text { (treatment effects) }^{2}\end{array}$ \\
\hline \multicolumn{6}{|l|}{ Plasma glucose } \\
\hline Mean conc, mmol/L $\mathrm{L}^{3}$ & $4.5 \pm 0.1$ & $4.4 \pm 0.1$ & $4.6 \pm 0.1$ & $4.4 \pm 0.2$ & $<0.001 *$ \\
\hline $\mathrm{t}=-1 \mathrm{~min}, \mathrm{mmol} / \mathrm{L}$ & $4.5 \pm 0.1$ & $3.9 \pm 0.1$ & $4.6 \pm 0.1$ & $4.2 \pm 0.1$ & $0.017^{*}$ \\
\hline Postdrink peak glucose, $\mathrm{mmol} / \mathrm{L}$ & $7.2 \pm 0.3$ & $6.2 \pm 0.3$ & $7.2 \pm 0.3$ & $6.4 \pm 0.4$ & $0.001^{*}$ \\
\hline Postdrink time to peak glucose, min & $43 \pm 5$ & $58 \pm 8$ & $45 \pm 7$ & $69 \pm 9$ & $0.006^{*}$ \\
\hline \multicolumn{6}{|l|}{ Plasma C-peptide } \\
\hline Mean conc, pmol/L ${ }^{3}$ & $231 \pm 41$ & $394 \pm 51$ & $321 \pm 60$ & $446 \pm 76$ & $0.002 *$ \\
\hline $\mathrm{t}=-1 \mathrm{~min}, \mathrm{pmol} / \mathrm{L}$ & $312 \pm 53$ & $687 \pm 126$ & $278 \pm 76$ & $589 \pm 75$ & $0.001 *$ \\
\hline \multicolumn{6}{|l|}{ Plasma GLP-1 } \\
\hline Mean conc, pmol/L³ & $19.2 \pm 1.2$ & $22.5 \pm 1.9$ & $19.9 \pm 1.4$ & $22.3 \pm 1.6$ & $0.002 *$ \\
\hline $\mathrm{t}=-1 \mathrm{~min}, \mathrm{pmol} / \mathrm{L}$ & $19.4 \pm 1.2$ & $22.1 \pm 2.1$ & $19.0 \pm 1.5$ & $26.0 \pm 2.5$ & $0.011^{*}$ \\
\hline
\end{tabular}

${ }^{1}$ Data are means \pm SEMs unless otherwise indicated, $n=14$. Data were analyzed using repeated-measures 2-way ANOVA with treatment and route of administration as factors. *Qunine significantly different from control. ID, intraduodenal; IG, intragastric; $\mathrm{QHCl}$, quinine hydrochloride.

${ }^{2}$ Only significant main effects or interactions are shown.

${ }^{3}$ Mean concentration calculated for $\mathrm{t}=-61$ to -1 min for IG conditions, and for $\mathrm{t}=-31$ to -1 min for ID conditions.

\section{Discussion}

Our study compared the effects of IG and ID administration of quinine on the plasma glucose response to a mixed-nutrient drink, and relations with plasma C-peptide and GLP-1 levels and gastric emptying, in healthy men. Our key findings were that quinine lowered plasma glucose and stimulated plasma Cpeptide and GLP-1, both alone and following the drink, and slowed gastric emptying of the drink, without any difference between the IG and ID routes of administration. These observations have important implications for the potential clinical use of bitter compounds to lower postprandial blood glucose.

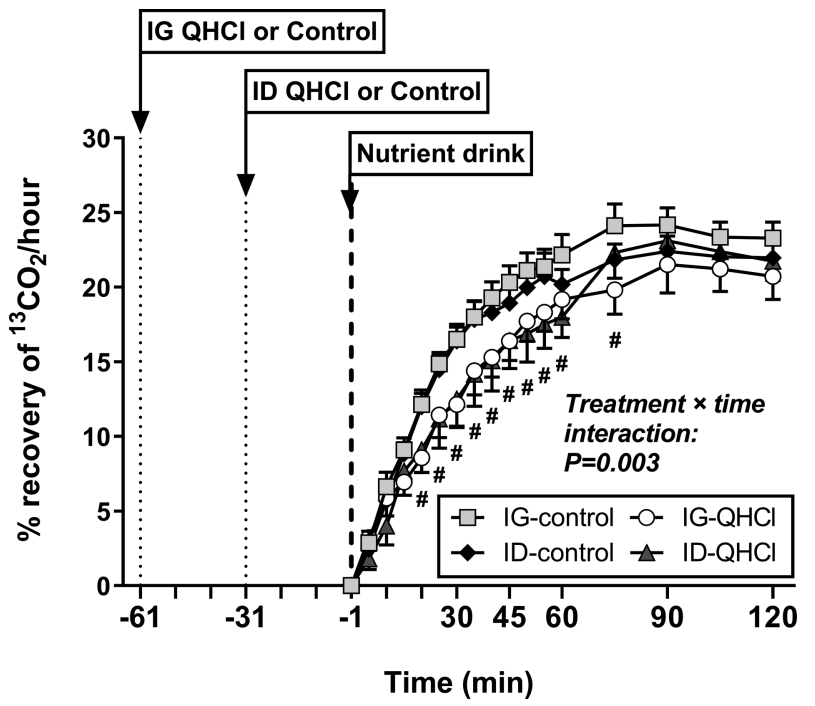

FIGURE 4 Gastric emptying of a mixed-nutrient drink, measured by ${ }^{13} \mathrm{C}$-acetate breath test, 60 min after IG, or 30 min after ID, administration of either $\mathrm{QHCl}(\mathrm{IG}-\mathrm{QHCl}$ or $\mathrm{ID}-\mathrm{QHCl}$, respectively) or control (IG-control or ID-control, respectively) in healthy men. Data were analyzed using repeated-measures 3-way ANOVA, with treatment, route of administration and time as factors. $\# \mathrm{OHCl}$ and control differ at that time, all $P<0.016$. Data are means \pm SEMs; $n=12$. ID, intraduodenal; IG, intragastric; $\mathrm{OHCl}$, quinine hydrochloride.
That quinine lowers plasma glucose confirms our recent findings that $600 \mathrm{mg}$ quinine, administered intragastrically, reduced the plasma glucose response to a mixed-nutrient drink consumed $30 \mathrm{~min}$ after quinine (25). In the current study we hypothesized that additional time would be required following IG administration for quinine to reach a sufficient number of bitter receptors, when compared with ID administration, because a greater number of bitter receptors has been reported in the duodenum, compared with the stomach (14). Accordingly, IG quinine was administered $60 \mathrm{~min}$, and ID quinine $30 \mathrm{~min}$, prior to the drink. The plasma glucose-lowering effect of quinine was comparable and substantial in both conditions. Thus, the time difference of $30 \mathrm{~min}$ between IG and ID quinine administration appears sufficient for IG quinine to empty into the duodenum to activate small intestinal bitter receptors or, alternatively, to activate a greater number of gastric bitter receptors. This result is promising, as administration into the stomach can be easily achieved using encapsulation technologies, which would also conceal the aversive taste of bitter compounds in a practical setting.

To our knowledge, this is only the second study that has evaluated the effects of a bitter compound, administered into the GI lumen, on insulin secretion (as measured by C-peptide) in humans. In our recent study in healthy men, IG administration of quinine, at doses of 275 or $600 \mathrm{mg}$, modestly stimulated insulin immediately before a mixed-nutrient drink, consumed $30 \mathrm{~min}$ later, and the insulin response to the nutrient drink was also enhanced (within $15 \mathrm{~min}$ ), associated with a lowering of plasma glucose within $30 \mathrm{~min}(25)$. Because the quinineinduced stimulation of insulin before the drink was small, but rising, we hypothesized that the interval of 30 min between IG quinine administration and drink consumption may have been insufficient for more substantive insulin stimulation. In the current study, quinine, in a dose of $600 \mathrm{mg}$, modestly stimulated C-peptide, within $30 \mathrm{~min}$ of ID, and $60 \mathrm{~min}$ of IG, administration, with no difference between the routes of administration, associated with lowering of fasting glucose. Cpeptide increased much more after the drink, and this rise was greater following both IG and ID quinine. An increase in insulin is likely to be primarily responsible for the reduction in plasma glucose. Indeed, we found an inverse relation between the early 

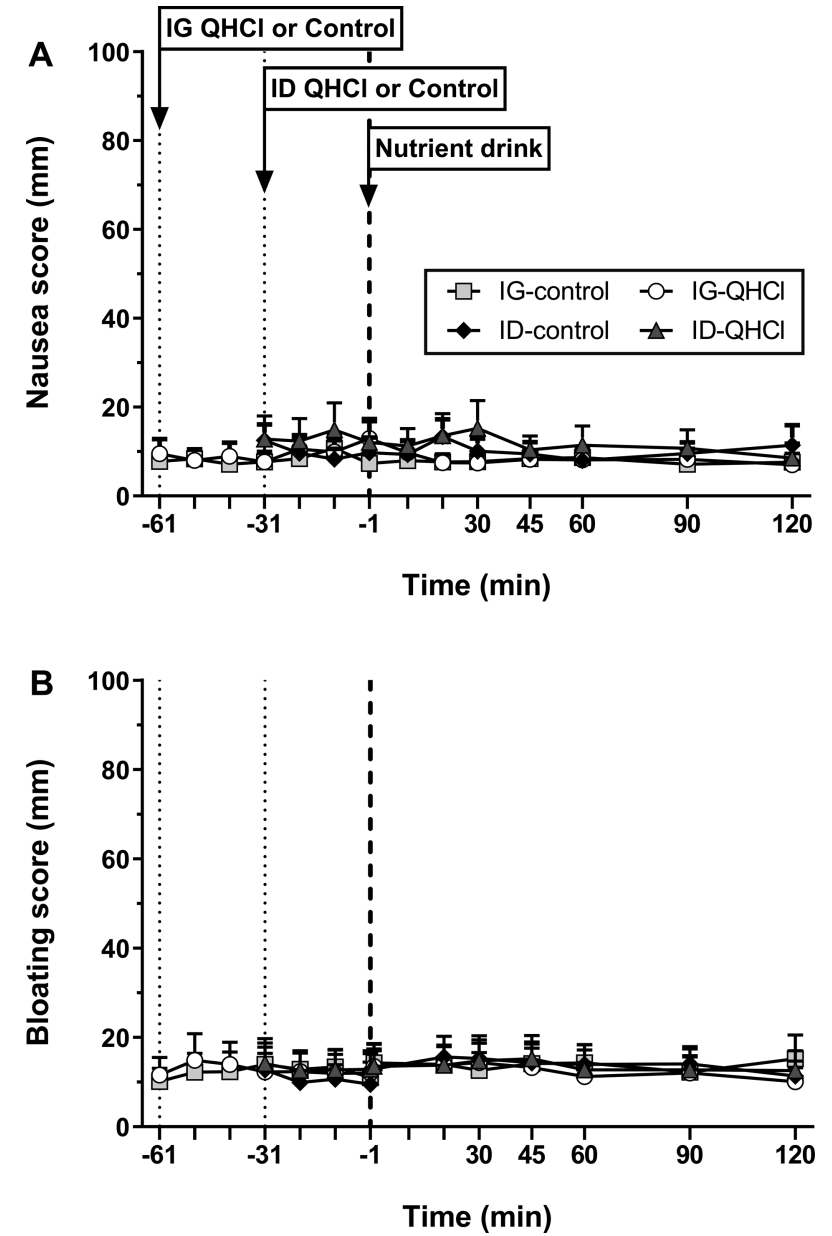

FIGURE 5 Scores for nausea $(A)$ and bloating $(B)$ in response to IG $\mathrm{QHCl}$ or control ( $\mathrm{t}=-61$ to $-1 \mathrm{~min}$; IG-QHCl or IG-control, respectively), or ID $\mathrm{QHCl}$ or control ( $\mathrm{t}=-31$ to $-1 \mathrm{~min}$; ID-QHCl or IDcontrol, respectively), and after a mixed-nutrient drink ( $t=0-120 \mathrm{~min}$ ) in healthy men. Data are expressed as means $\pm \mathrm{SEMs} ; n=14$. ID, intraduodenal; IG, intragastric; $\mathrm{OHCl}$, quinine hydrochloride.

rise in plasma glucose postdrink and the rise in C-peptide immediately before the drink. The mechanism(s) underlying the effect of quinine to stimulate insulin secretion are speculative. The absorption of quinine into the bloodstream may stimulate insulin by directly activating receptors on pancreatic beta cells. This is likely, as intravenous quinine, when used to treat malaria patients, markedly increases insulin, associated, not infrequently, with hypoglycemia $(35,36)$. Moreover, while it is unclear whether TAS2Rs are present on human pancreatic beta cells, quinine induces insulin secretion from isolated murine pancreatic beta cells in vitro (37). While we did not measure glucagon in the current study, we have shown previously that quinine stimulates glucagon secretion modestly (25); thus, it is possible that glucagon may have somewhat attenuated the glucose-lowering effect of quinine.

A number of bitter compounds, including berberine, 1,10phenanthroline, and denatonium benzoate, have been reported to stimulate GLP-1 release from enteroendocrine cells (18, $20,38)$. In our previous study (25), plasma GLP-1 increased modestly in response to IG quinine at the doses of 275 and $600 \mathrm{mg}$. In the current study, both ID and IG administration of $600 \mathrm{mg}$ quinine modestly stimulated GLP-1, with no difference between the 2 routes at $t=-1 \mathrm{~min}$. This suggests that IG administration requires a longer time for an effect comparable to ID administration and, therefore, that exposure of small intestinal bitter receptors to quinine is most likely required for stimulation of GLP-1 release. The role of GLP-1 in the observed glucose-lowering by quinine is unclear. While some studies have shown that the insulinotropic effect of GLP-1 requires circulating glucose concentrations of $\sim 7-8 \mathrm{mmol} / \mathrm{L}(33,39)$, other studies have reported that glucose concentrations of $\sim 4-$ $5 \mathrm{mmol} / \mathrm{L}$ are sufficient (40). In the current study, plasma glucose reached $\sim 6-7 \mathrm{mmol} / \mathrm{L}$, thus, the contribution of GLP-1 to the stimulation of insulin was probably modest, and the magnitude of this effect would need to be established with the use of a GLP-1 receptor antagonist.

Gastric emptying is a key determinant of postprandial blood glucose regulation. In contrast to our previous study, in which quinine was administered intragastrically $30 \mathrm{~min}$ before a mixed-nutrient drink, in the current study, administration of the same dose of quinine, either intragastrically $60 \mathrm{~min}$, or intraduodenally $30 \mathrm{~min}$, before the drink, slowed gastric emptying. The underlying mechanisms are unknown, but may potentially involve the release of gut hormones, including CCKand GLP-1. Both have potent effects to slow gastric emptying in humans $(1,41,42)$. Since GLP-1 was increased by quinine immediately before consumption of the nutrient drink, it is possible that GLP-1 contributed to slowing of gastric emptying, while the effect of quinine on CCK release remains to be established. The slowing of gastric emptying most likely contributed to postprandial blood glucose-lowering, which was apparent for the first postprandial hour. Indeed, we found a correlation between the early lowering of postprandial glucose and slowing of gastric emptying. In contrast, in our previous study (25), in which quinine stimulated insulin, but did not slow gastric emptying, glucose-lowering occurred only at around 30 min postmeal. Thus, when quinine administration is carefully targeted, a potent and more prolonged effect to lower postprandial blood glucose can be achieved by activating both the secretion of insulin and slowing of gastric emptying. It is also important to note that slowing of gastric emptying was not due to an aversive effect of quinine, since participants did not report any nausea. Studies in patients with type 2 diabetes are now warranted to evaluate potential clinical benefits.

It is appropriate to recognize some limitations of our study. We did not measure circulating quinine concentrations. We only included male participants to avoid any confounding effect of the menstrual cycle on gastric emptying (43), however, female participants have been reported to have lower oral detection thresholds for denatonium benzoate (44), suggesting that they may also be more sensitive to intraluminal bitter stimuli. We did not measure plasma ghrelin or motilin concentrations, which are modulated by bitter substances $(45,46)$. However, since both hormones, when administered exogenously, accelerate gastric emptying $(47,48)$, and at least ghrelin is suppressed in the postprandial state (1), they are unlikely to be involved in the observed slowing of gastric emptying by quinine. Our study was designed to evaluate the glycemic and gastric emptying effects of quinine, using a standardized drink. Thus, the evaluation of energy intake, which requires an ad libitum meal, was not possible, and we did not measure appetite perceptions. Finally, we cannot exclude the possibility that the effects of quinine observed in our study, or previous studies using similarly high doses, might be due to effects that did not involve activation of bitter-receptors on enteroendocrine cells, e.g., direct effects of circulating quinine on smooth muscle or pancreatic beta cells. However, this was a "proof-of-principle" study, and given the 
potent effects that we observed, future studies will be able to use lower doses. Moreover, the use of specific bitter-receptor antagonists would assist in answering this question; however, these antagonists are currently not available for use in humans.

In conclusion, our study established that quinine, when allowed to sufficiently interact with small intestinal bitter receptors, reduces postprandial blood glucose by stimulating glucoregulatory functions, including C-peptide secretion and slowing of gastric emptying, while the role of GLP-1 is somewhat uncertain. Nevertheless, this study demonstrates potent blood glucose-lowering effects of quinine in healthy people with good glycemic control, thus warranting further research to investigate the suitability of this bitter compound to improve postprandial blood glucose in people with type 2 diabetes or impaired glucose tolerance.

\section{Acknowledgments}

We thank our biostatistician, Kylie Lange, Centre of Research Excellence in Translating Nutritional Science to Good Health, The University of Adelaide, for statistical support, and Scott Standfield for performing the hormone assays.

The authors' responsibilities were as follows-BDR, VB, and PR: conducted research, analyzed data, performed statistical analysis, and wrote the manuscript; PCEF: conducted the research; $\mathrm{MH}$ : designed research, analyzed data, and wrote the manuscript; CF-B: designed the research, analyzed data, wrote the manuscript, and had primary responsibility for the project; and all authors: read and approved the final version of the manuscript.

\section{References}

1. Steinert RE, Feinle-Bisset C, Asarian L, Horowitz M, Beglinger C, Geary N. Ghrelin, CCK, GLP-1, and PYY(3-36): secretory controls and physiological roles in eating and glycemia in health, obesity, and after RYGB. Physiol Rev 2017;97(1):411-63.

2. Marathe CS, Rayner CK, Jones KL, Horowitz M. Glucagon-like peptides 1 and 2 in health and disease: a review. Peptides 2013;44: 75-86.

3. Van Avesaat M, Troost FJ, Ripken D, Peters J, Hendriks HF, Masclee AA. Intraduodenal infusion of a combination of tastants decreases food intake in humans. Am J Clin Nutr 2015;102(4):729-35.

4. Ryan AT, Luscombe-Marsh ND, Saies AA, Little TJ, Standfield S, Horowitz M, Feinle-Bisset C. Effects of intraduodenal lipid and protein on gut motility and hormone release, glycemia, appetite, and energy intake in lean men. Am J Clin Nutr 2013;98(2):300-11.

5. Feltrin KL, Little TJ, Meyer JH, Horowitz M, Smout AJ, Wishart J, Pilichiewicz AN, Rades T, Chapman IM, Feinle-Bisset C. Effects of intraduodenal fatty acids on appetite, antropyloroduodenal motility, and plasma CCK and GLP-1 in humans vary with their chain length. Am J Physiol Regul Integr Comp Physiol 2004;287(3): R524-33.

6. Ma J, Stevens JE, Cukier K, Maddox AF, Wishart JM, Jones KL, Clifton PM, Horowitz M, Rayner CK. Effects of a protein preload on gastric emptying, glycemia, and gut hormones after a carbohydrate meal in dietcontrolled type 2 diabetes. Diabetes Care 2009;32(9):1600-2.

7. Müller TD, Finan B, Bloom SR, D’Alessio D, Drucker DJ, Flatt PR, Fritsche A, Gribble F, Grill HJ, Habener JF, et al. Glucagon-like peptide 1 (GLP-1). Mol Metab 2019;30:72-130.

8. Deane AM, Nguyen NQ, Stevens JE, Fraser RJ, Holloway RH, Besanko LK, Burgstad C, Jones KL, Chapman MJ, Rayner CK, et al. Endogenous glucagon-like peptide- 1 slows gastric emptying in healthy subjects, attenuating postprandial glycemia. J Clin Endocrinol Metab 2010;95(1):215-21.

9. Flint A, Raben A, Astrup A, Holst JJ. Glucagon-like peptide 1 promotes satiety and suppresses energy intake in humans. J Clin Invest 1998;101(3):515-20.
10. Little TJ, Pilichiewicz AN, Russo A, Phillips L, Jones KL, Nauck MA, Wishart J, Horowitz M, Feinle-Bisset C. Effects of intravenous glucagonlike peptide-1 on gastric emptying and intragastric distribution in healthy subjects: relationships with postprandial glycemic and insulinemic responses. J Clin Endocrinol Metab 2006;91(5):1916-23.

11. Astrup A, Rossner S, Van Gaal L, Rissanen A, Niskanen L, Al Hakim M, Madsen J, Rasmussen MF, Lean ME. Effects of liraglutide in the treatment of obesity: a randomised, double-blind, placebo-controlled study. Lancet North Am Ed 2009;374(9701):1606-16.

12. Buse JB, Rosenstock J, Sesti G, Schmidt WE, Montanya E, Brett $\mathrm{JH}$, Zychma M, Blonde L. Liraglutide once a day versus exenatide twice a day for type 2 diabetes: a 26-week randomised, parallelgroup, multinational, open-label trial (LEAD-6). Lancet North Am Ed 2009;374(9683):39-47.

13. Marathe CS, Horowitz M, Trahair LG, Wishart JM, Bound M, Lange K, Rayner CK, Jones KL. Relationships of early and late glycemic responses with gastric emptying during an oral glucose tolerance test. J Clin Endocrinol Metab 2015;100(9):3565-71.

14. Wu SV, Rozengurt N, Yang M, Young SH, Sinnett-Smith J, Rozengurt E. Expression of bitter taste receptors of the T2R family in the gastrointestinal tract and enteroendocrine STC-1 cells. Proc Natl Acad Sci 2002;99(4):2392-7.

15. Avau B, Rotondo A, Thijs T, Andrews CN, Janssen P, Tack J, Depoortere I. Targeting extra-oral bitter taste receptors modulates gastrointestinal motility with effects on satiation. Sci Rep 2015;5:15985.

16. Xie C, Wang X, Young RL, Horowitz M, Rayner CK, Wu T. Role of intestinal bitter sensing in enteroendocrine hormone secretion and metabolic control. Front Endocrinol 2018;9:576.

17. Janssen S, Laermans J, Verhulst PJ, Thijs T, Tack J, Depoortere I. Bitter taste receptors and $\alpha$-gustducin regulate the secretion of ghrelin with functional effects on food intake and gastric emptying. Proc Natl Acad Sci U S A 2011;108(5):2094-9.

18. Yu Y, Hao G, Zhang Q, Hua W, Wang M, Zhou W, Zong S, Huang M, Wen X. Berberine induces GLP-1 secretion through activation of bitter taste receptor pathways. Biochem Pharmacol 2015;97(2):173-7.

19. Kim KS, Egan JM, Jang HJ. Denatonium induces secretion of glucagonlike peptide-1 through activation of bitter taste receptor pathways. Diabetologia 2014;57(10):2117-25.

20. Pham H, Hui H, Morvaridi S, Cai J, Zhang S, Tan J, Wu V, Levin N, Knudsen B, Goddard WA, 3rd, et al. A bitter pill for type 2 diabetes? The activation of bitter taste receptor TAS2R38 can stimulate GLP-1 release from enteroendocrine L-cells. Biochem Biophys Res Commun 2016;475(3):295-300.

21. Kok BP, Galmozzi A, Littlejohn NK, Albert V, Godio C, Kim W, Kim SM, Bland JS, Grayson N, Fang M, et al. Intestinal bitter taste receptor activation alters hormone secretion and imparts metabolic benefits. Mol Metab 2018;16:76-87.

22. Huang TN, Lu KN, Pai YP, Chin H, Huang CJ. Role of GLP-1 in the hypoglycemic effects of wild bitter gourd. Evid Based Complement Alternat Med 2013;2013:625892.

23. Mennella I, Fogliano V, Ferracane R, Arlorio M, Pattarino F, Vitaglione P. Microencapsulated bitter compounds (from Gentiana lutea) reduce daily energy intakes in humans. Br J Nutr 2016;116(10): 1841-50.

24. Bitarafan V, Fitzgerald PCE, Little TJ, Meyerhof W, Wu T, Horowitz M, Feinle-Bisset C. Effects of intraduodenal infusion of the bitter tastant, quinine, on antropyloroduodenal motility, plasma cholecystokinin, and energy intake in healthy men. J Neurogastroenterol Motil 2019;25(3):413-22.

25. Bitarafan V, Fitzgerald PCE, Little TJ, Meyerhof W, Jones KL, Wu T, Horowitz M, Feinle-Bisset C. Intragastric administration of the bitter tastant quinine lowers the glycemic response to a nutrient drink without slowing gastric emptying in healthy men. Am J Physiol Regul Integr Comp Physiol 2020;318(2):R263-73.

26. Andreozzi P, Sarnelli G, Pesce M, Zito FP, Alessandro AD, Verlezza V, Palumbo I, Turco F, Esposito K, Cuomo R. The bitter taste receptor agonist quinine reduces calorie intake and increases the postprandial release of cholecystokinin in healthy subjects. J Neurogastroenterol Motil 2015;21(4):511-9.

27. Stunkard AJ, Messick S. The three-factor eating questionnaire to measure dietary restraint, disinhibition and hunger. J Psychosom Res 1985;29(1):71-83.

28. Steinert RE, Landrock MF, Ullrich SS, Standfield S, Otto B, Horowitz M, Feinle-Bisset C. Effects of intraduodenal infusion of the 
branched-chain amino acid leucine on ad libitum eating, gut motor and hormone functions, and glycemia in healthy men. Am J Clin Nutr 2015;102(4):820-7.

29. Mossi S, Meyer-Wyss B, Beglinger C, Schwizer W, Fried M, Ajami A, Brignoli R. Gastric emptying of liquid meals measured noninvasively in humans with [13C]acetate breath test. Digest Dis Sci 1994;39(12 Suppl):107S.

30. Chale-Rush A, Burgess JR, Mattes RD. Evidence for human orosensory (taste?) sensitivity to free fatty acids. Chem Senses 2007;32(5):423-31.

31. Polonsky KS, Rubenstein AH. C-peptide as a measure of the secretion and hepatic extraction of insulin. Pitfalls and limitations. Diabetes 1984;33(5):486-94.

32. Ullrich SS, Fitzgerald PC, Schober G, Steinert RE, Horowitz M, Feinle-Bisset C. Intragastric administration of leucine or isoleucine lowers the blood glucose response to a mixed-nutrient drink by different mechanisms in healthy, lean volunteers. Am J Clin Nutr 2016;104(5):1274-84.

33. Nauck MA, Kleine N, Orskov C, Holst JJ, Willms B, Creutzfeldt W. Normalization of fasting hyperglycaemia by exogenous glucagonlike peptide 1 (7-36 amide) in type 2 (non-insulin-dependent) diabetic patients. Diabetologia 1993;36(8):741-4.

34. Bland JM, Altman DG. Calculating correlation coefficients with repeated observations: part 1-correlation within subjects. BMJ 1995;310(6977):446.

35. White NJ, Warrell DA, Chanthavanich P, Looareesuwan S, Warrell MJ, Krishna S, Williamson DH, Turner RC. Severe hypoglycemia and hyperinsulinemia in falciparum malaria. N Engl J Med 1983;309(2): 61-6.

36. Okitolonda W, Delacollette C, Malengreau M, Henquin JC. High incidence of hypoglycaemia in African patients treated with intravenous quinine for severe malaria. BMJ 1987;295(6600):716-8.

37. Henquin JC, Horemans B, Nenquin M, Verniers J, Lambert AE. Quinine-induced modifications of insulin release and glucose metabolism by isolated pancreatic islets. FEBS Lett 1975;57(3): 280-4.

38. Yue X, Liang J, Gu F, Du D, Chen F. Berberine activates bitter taste responses of enteroendocrine STC-1 cells. Mol Cell Biochem 2018;447(1-2):21-32.
39. Holst JJ. The physiology of glucagon-like peptide 1. Physiol Rev 2007;87(4):1409-39.

40. Degn KB, Brock B, Juhl CB, Djurhuus CB, Grubert J, Kim D, Han J, Taylor K, Fineman M, Schmitz O. Effect of intravenous infusion of exenatide (synthetic exendin-4) on glucose-dependent insulin secretion and counterregulation during hypoglycemia. Diabetes 2004;53(9):2397-403.

41. Nauck MA, Niedereichholz U, Ettler R, Holst JJ, Orskov C, Ritzel R, Schmiegel WH. Glucagon-like peptide 1 inhibition of gastric emptying outweighs its insulinotropic effects in healthy humans. Am J Physiol 1997;273(5):E981-8.

42. Liddle RA, Morita ET, Conrad CK, Williams JA. Regulation of gastric emptying in humans by cholecystokinin. J Clin Invest 1986;77(3): 992-6.

43. Brennan IM, Feltrin KL, Nair NS, Hausken T, Little TJ, Gentilcore D, Wishart JM, Jones KL, Horowitz M, Feinle-Bisset C. Effects of the phases of the menstrual cycle on gastric emptying, glycemia, plasma GLP-1 and insulin, and energy intake in healthy lean women. Am J Physiol Gastrointest Liver Physiol 2009;297(3):G602-10.

44. Deloose E, Janssen P, Corsetti M, Biesiekierski J, Masuy I, Rotondo A, Van Oudenhove L, Depoortere I, Tack J. Intragastric infusion of denatonium benzoate attenuates interdigestive gastric motility and hunger scores in healthy female volunteers. Am J Clin Nutr 2017;105(3):580-8.

45. Deloose E, Corsetti M, Van Oudenhove L, Depoortere I, Tack J. Intragastric infusion of the bitter tastant quinine suppresses hormone release and antral motility during the fasting state in healthy female volunteers. Neurogastroenterol Motil 2018;30(1):e13171.

46. Iven J, Biesiekierski JR, Zhao D, Deloose E, O’Daly OG, Depoortere I, Tack J, Van Oudenhove L. Intragastric quinine administration decreases hedonic eating in healthy women through peptide-mediated gut-brain signaling mechanisms. Nutr Neurosci 2019;22(12):850-62.

47. Levin F, Edholm T, Schmidt PT, Grybäck P, Jacobsson H, Degerblad M, Höybye C, Holst JJ, Rehfeld JF, Hellström PM, et al. Ghrelin stimulates gastric emptying and hunger in normal-weight humans. J Clin Endocrinol Metab 2006;91(9):3296-302.

48. Ohno T, Mochiki E, Kuwano H. The roles of motilin and ghrelin in gastrointestinal motility. Int J Pept 2010;2010:820794. 